\title{
Climate change impacts on intensity duration frequency curves of precipitation: A case study of Shiraz synoptic station, Iran
}

\author{
A.ROSHAN ${ }^{1}$, H. SEDGHI ${ }^{2}$,R.A.SHARIFAN ${ }^{3}$ and J.PORHEMMAT ${ }^{4}$ \\ ${ }^{1,2}$ Department of Agricultural Systems Engineering, Science and Research Branch, Islamic Azad University, Tehran, Iran. \\ ${ }^{3}$ Department of Water Resources Engineering, Shiraz Branch, Islamic Azad University, Shiraz, Iran. \\ ${ }^{4}$ Soil Conservation and Watershed Management Research Institute-Agricultural Research, Education and Extension \\ Organization, Shahid shafiee Street, Tehran, Iran . \\ Corresponding author E-mail: rafshinus@yahoo.com
}

\begin{abstract}
Intensity-duration-frequency (IDF) curves are among the standard design tools for many engineering applications such as urban drainage management. Since climate change may considerably affect precipitation, updating of IDF curves is highly necessary. The present study aims to examine the impacts of climate change on IDF curves of Shiraz synoptic station using downscaled outputs of Hadcm 3 AOGCM under various emission scenarios (A1B, A2,B1) applying larswg-5 model for the period of 2046 to 2065. The fitted Gumbel distribution was used to estimate the maximum short-term precipitation quantiles in the base period (1968-2000) and the verified empirical Bell type equation was used for the future period. The results show that the mean of maximum daily precipitation and annual precipitation will decrease in the future. Also, the maximum precipitation intensities up to $60 \mathrm{~min}$ duration will reduce from $0.15 \mathrm{~mm} \mathrm{hr}^{-1}$ to about $10.79 \mathrm{~mm} \mathrm{hr}^{-1}$ compared to the observed period in all returns periods and various scenarios. Overall, there were no tangible changes in intensities for durations higher than 60 $\mathrm{min}$. The highest reduction in precipitation intensity would be at the 20 min duration with 100 -year return period in the A2 scenario.
\end{abstract}

Keywords: Climate change, IDF, Lars wg-5, Hadcm3

The precipitation intensity-duration-frequency (IDF) curves are one of the main tools to design of hydrosystems and to estimate the design flow, especially in ungauged areas (Afrin et al. 2015). Nowadays, in most areas of the world, the estimation of IDF curves and equations is done using statistical frequency analysis under stationarity condition. Climate change is among the main factors causing changes in long-term descriptive statistics of precipitation and distorts the stationarity assumption. Therefore, estimated quantiles of extreme and IDF curves, in general, would not have sufficient precision and reliability and may require modification. The potential effect of climate change on extreme events is also approved (Akbari et al. 2015; Mirhosseini et al. 2013), so that an increasing trend in maximum daily precipitation and shorter durations are reported (Fadhel et al. 2017;Rodriguez et al. 2014). Numerous studies have been conducted all over the world and more specifically in the United States and Canada about the effect of climate change on extreme precipitation and updating IDF curves (Mamo 2015; Zahmatkesh 2015). Most of the studies suggest increasing the precipitation intensity with certain duration at various return periods (Afrin et al. 2015; Fadhel et al. 2017;Mamo 2015; Solaiman and Simonovic 2011;Zahmatkesh et al. 2015) and some of them also have reported decreasing intensity at short duration (Akbari et al. 2015; Mirhosseini et al. 2013). All these studies employ Atmospheric-Ocean General Circulation Models (AOGCM) or regional climate models (RCM) under different emission scenarios. several methods have been used to disaggregate daily precipitation to shorter base times or calculate the maximum intensity at various durations and probable levels as a function of maximum daily precipitation quantiles. Among most important methods in this regard are method of fragment (MOF) (Fadhel et al. 2017; Pereira et al. 2014; Solaiman and Simonovic 2011), constant scale method (Afrin et al. 2015; Rodriguez et al. 2014), constant climate change factor (Rodriguez et al. 2014), Equidistant quantiles (Singh et al. 2016), hourly change factor (Zahmatkesh et al. 2015), disaggregation based on observed severe daily precipitation histograms (Akbari et al. 2015) and regional Bell type equations (Bakhtiari et al. 2015) that estimate maximum short-term 

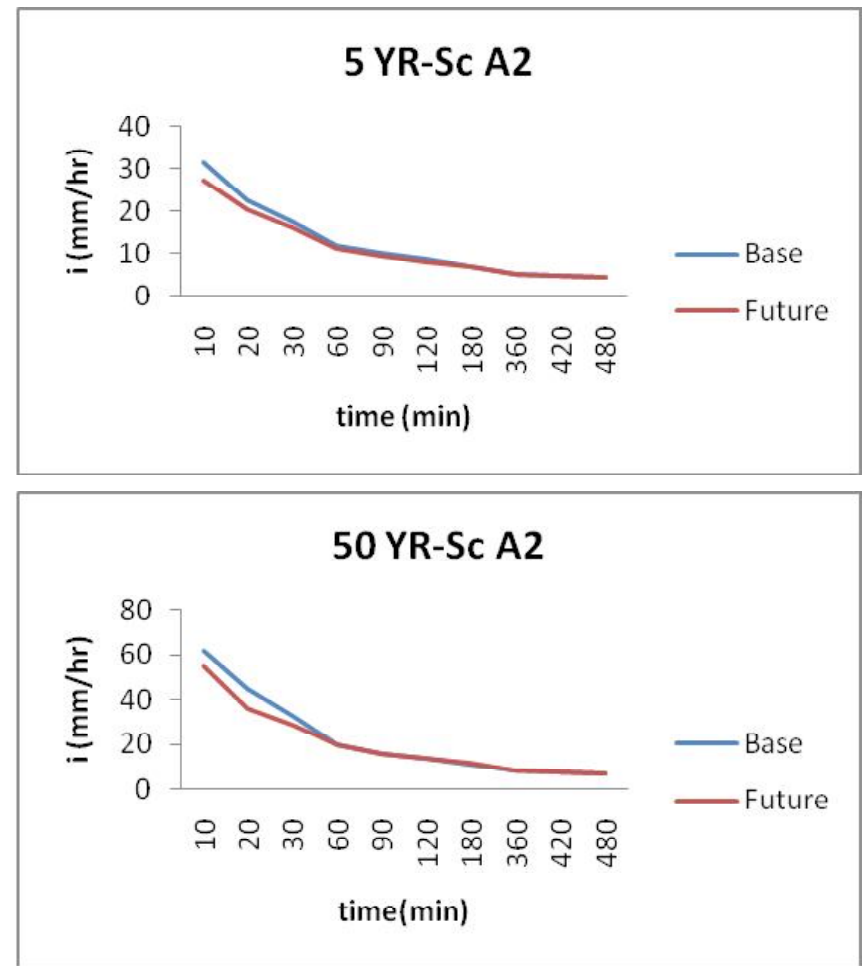

Fig. 1: IDF curves of base and future period under A2 Scenario precipitation quantiles as a function of 1 hour maximum precipitation quantiles. The present study aims to examine the impacts of climate change on IDF curves of Shiraz Synoptic station using downscaled outputs of appropriate AOGCM under various emission scenarios applying LARSWG-5 model for the period of 2046 to 2065. Data frequency analysis was applied to estimate the maximum short-term precipitation quantiles at the base period (19682000) and verified regional bell type equation used for a future period (2046-2065).

\section{MATERIALS AND METHODS}

\section{Study area and data}

Shiraz is one of the largest cities in Iran and at the center of Fars Province in the Zagros mountainous area. The synoptic weather station is located at the longitude of $52^{\circ}$ $36^{~ ' E}$ and latitude of $29^{\circ} 32^{\prime} \mathrm{N}$ at a height of 1,484 meters above sea level data on daily minimum and maximum temperatures, precipitation, sunshine, and recorded hyetographs for the 1968-2000 base period. These data were obtained from the Meteorological Organization of Fars province.

Extraction of base period maximum short-term precipitations quantiles $\left(R^{T}\right)$ and IDF curves

The base period IDF curves were calculated using

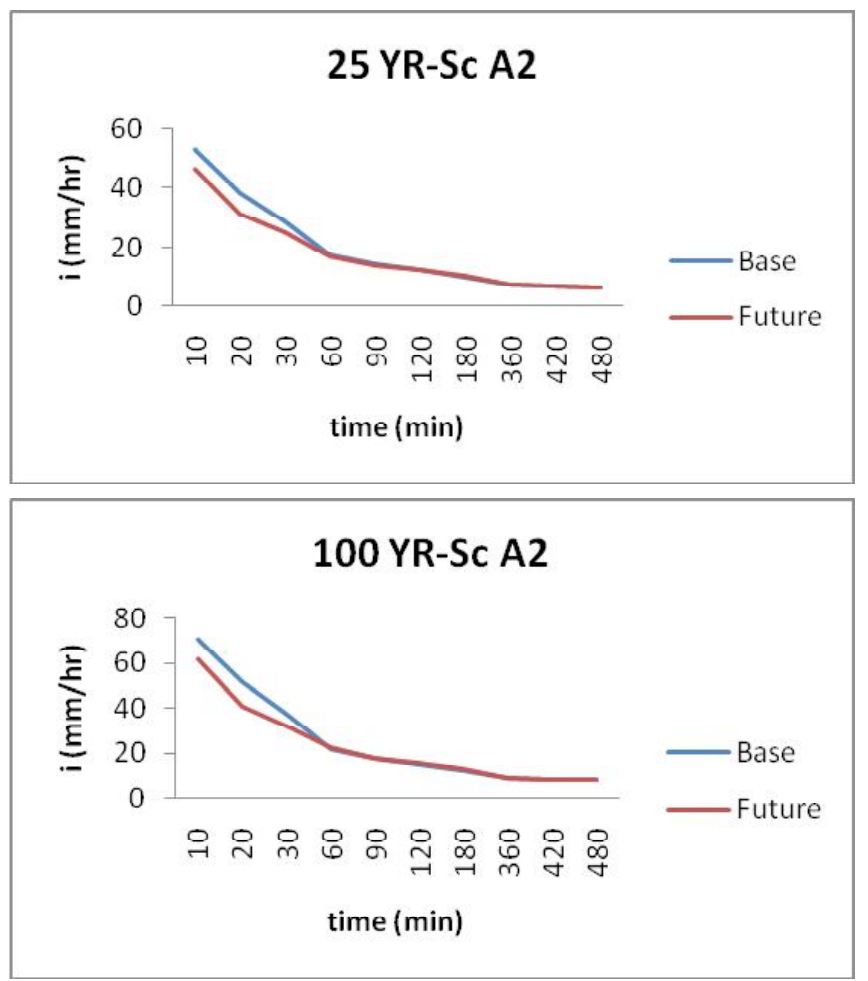

recorded storm hyetographs and based on the methods proposed by Chow et al. (1988). Fitting of appropriate statistical distribution function on the annual maximum intensities of desirable short durations is carried out using the HYFRAN PLUS software and applying the maximum likelihood method. After calculating the maximum shortterm intensitiy quantiles $\left(\mathrm{I}_{\mathrm{t}}^{\mathrm{T}}\right)$ and precipitation quantiles $\left(\mathrm{R}_{\mathrm{t}}^{\mathrm{T}}\right)$ in the desired durations, the IDF curves are drawn and the relationship between the intensity and duration of precipitation in various return period is determined.

\section{Maximum short-term precipitation quantiles $\left(R^{T}\right)$ equation}

Following the estimation of the maximum precipitation quantiles in different durations of the base period, it is necessary to fit the appropriate relationship between them and other observed or simulated variables that can be used in the future. In previous studies (Ghahraman and Abkhezr (2004)) in Iran like empirical Bell equation (Bell 1969) the general equation $\mathrm{R}_{\mathrm{t}}^{\mathrm{T}}=\mathrm{A} \cdot \mathrm{t}^{\mathrm{B}} \cdot \mathrm{R}_{60}^{\mathrm{T}}$ has been presented, where $\mathrm{R}_{60}^{\mathrm{T}}$ is a maximum hourly precipitation in $\mathrm{T}$ year return period and $\mathrm{A}$ and $\mathrm{B}$ are constant coefficients calibrated regionally using the results of storm analysis in 7 regions of Iran. The $\mathrm{R}_{60}^{\mathrm{T}}$ is determined as a function of the $\mathrm{R}_{60}^{10}$ and the return period $(\mathrm{T})$ and the $\mathrm{R}_{60}^{10}$ is a function of the mean of maximum daily $\left(\mathrm{P}_{\text {daily }}\right)$ and annual precipitation $\left(\mathrm{p}_{\text {year }}\right)$ during the data period. These variables $\left(\mathrm{P}_{\text {daily }}, \mathrm{P}_{\text {year }}\right)$ can be provided using AOGCM and suitable weather generator model. To apply 
Table 1: Error Indices of different method (Sepahkhah, Vaziri and Ghahraman-Abkhezr)

\begin{tabular}{llll}
\hline Method & $\begin{array}{l}\text { Ghahraman }- \\
\text { Abkhezr }\end{array}$ & Vaziri & $\begin{array}{l}\text { Ghahraman- } \\
\text { Sepaskhah }\end{array}$ \\
\hline $\mathrm{R}^{2}$ & 0.993 & 0.994 & 0.987 \\
RMSE & 1.81 & 1.65 & 12.08 \\
\hline
\end{tabular}

these equations, it is necessary to verify them based on desirable station data. This verification is done by comparing the quantiles obtained from the frequency analysis and empirical equations. Selection of the best equation was based on error indices such as $\mathrm{R}^{2}$ and RMSE.

\section{Ghahraman and Sepaskhah equation (1990)}

$$
\begin{aligned}
& R_{t}^{T}=(0.4055+0.2636 \operatorname{Ln}(T-0.44))\left(-0.242+1.2452 t_{(h r)}^{0.2674}\right) \mathrm{R}_{60}^{10} \\
& R_{60}^{10}=2.2598 P_{\text {daily }}^{1.1374} P_{\text {year }}^{-0.3072}
\end{aligned}
$$

\section{Vaziri equation (1991)}

$$
\begin{aligned}
& R_{t}^{T}=(0.3866+0.2659 \operatorname{Ln}(T-0.0001))\left(0.1878+0.8281 t_{(h r)}^{(0.5998)}\right) R_{60}^{10}(3) \\
& R_{t}^{T}=(0.4549+0.2410 \operatorname{Ln}(T-0.3290))\left(0.0321+1.0279 t_{(h r)}^{(0.5198)}\right) R_{60}^{10} \\
& \text { If } \boldsymbol{P}_{\text {daily }} \leq \mathbf{6 8} \text {, then: } \\
& R_{60}^{10}=\left(1.239-0.2369 \mathrm{Ln}\left(\mathrm{P}_{\text {daily }}\right)\right) \mathrm{P}_{\text {daily }}
\end{aligned}
$$

\section{Ghahraman-Abkhezr equation (2004)}

$$
R_{60}^{10}=e^{0.291}\left(\mathrm{p}_{\text {daily }}\right)^{0.694}
$$

\section{For 10 minute $\leq t \leq 2$ hr precipitation}

$$
R_{t}^{T}=0.1372 \mathrm{t}^{0.4778}[0.4608+0.2349 \operatorname{Ln}(T-0.62)] R_{60}^{10}
$$

For 2 hour $<t \leq 9$ hour precipitation:

$$
R_{t}^{T}=0.2009 \mathrm{t}^{0.3937}[0.5565+0.1948 \operatorname{Ln}(T-0.8)] R_{60}^{10}
$$

\section{Future daily weather generation}

There are various methods for simulating climatic variables in the future period, with the most reliable of them being to use the output of a three-dimensional AOGCM. The AOGCM is based on the physical laws and is presented by mathematical equations. In this research, downscaled outputs of appropriate AOGCM under B1, A2, and A1B scenarios applying LARS-WG5 Stochastic Weather Generator have been used for the future (2046-2065) data generation. The appropriate global climate model is selected based on outputs verification in the base period (1970-2000) among eight AOGCM:CNRCM3, GFDLCM2, HADCM3, HADGEM, INCM3, IPSLCM4, MIHR, NCCCSM3. Lars-WG5 is one of the best stochastic weather generator models for generating daily precipitation, maximum and minimum temperatures under the base and future climatic conditions. LARSWG-5 incorporates predictions from $15 \mathrm{GCMs}$, as used in the IPCC assessment report IV, and climate projections are available for the special reports on emissions scenarios A1B, A2,B1 for most of $15 \mathrm{GCMs}$. Several studies have shown the better performance of the LARS-WG5 model with other random weather generators. Generation of the future daily weather using the LARS-WG5 model is done in three stages of calibration, validation and data generation (Semenov et al 2011).

\section{Maximum short-term precipitation quantiles and IDF curves under different scenarios}

The maximum short-term precipitation quantiles can be calculated using the verified bell type equation and an average of maximum daily precipitation and mean annual precipitation during the 2046-2046 period under A1B, A2, and $B 1$ scenarios. Finally, IDF curves are plotted the same as the base period.

\section{RESULTS AND DISCUSSION}

\section{Maximum short-term precipitation quantiles and IDF curves in base period (1968-2000)}

Fitting of different statistical distributions on the maximum annual short-term precipitation intensities at various duration showed that the Gumbel distribution with p-values from 0.09 up to 0.57 and minimum AIC (from 91.93 up to 204.72) is the best. Fig. 2 shows the IDF curves based on Gumbel distribution.

\section{Verified equation of short-term precipitation quantiles}

After calculating the quantiles using three mentioned methods (Ghahraman-Sepaskhah 1990, Vaziri 1991, and Ghahraman and Abkhezr, 2004) and comparing them with results of frequency analysis, the statistical indices of $\mathrm{R}^{2}$ and RMSE were determined for each method and presented in Table 1. Since the determination coefficient $\left(\mathrm{R}^{2}\right)$ for all three methods is high and close together, the Vaziri's (1991) method was selected as the best method with the lowest RMSE and highest $\mathrm{R}^{2}$. The method of Ghahraman-Sepahkhah (1990) was discarded due to its high RMSE.

\section{Lars-Wg5 model calibration}

Table 2 shows the mean and standard deviation of simulated and observed monthly precipitation along with the results of statistical tests at the final run of the model. As 
Table 2: Descriptive statistics of simulated and observed precipitation in the base period

\begin{tabular}{lcccccccccccc}
\hline $\begin{array}{l}\text { Statistical } \\
\text { Parameter }\end{array}$ & Jan & Feb & Mar & Apr & May & June & July & Aug & Sep & Oct & Nov & Dec \\
\hline Mean(OBS) & 88.0 & 54.3 & 61.3 & 24.6 & 7.2 & 0.4 & 0.9 & 0.9 & 0.0 & 6.4 & 18.9 & 73.0 \\
SD(OBS) & 55.8 & 46.3 & 41.3 & 20.1 & 12.5 & 1.2 & 3.4 & 4.0 & 0.0 & 14.5 & 27.7 & 61.2 \\
Mean(SIM) & 80.6 & 57.7 & 55.4 & 27.1 & 11.7 & 0.5 & 0.7 & 0.8 & 0.0 & 5.8 & 15.8 & 77.9 \\
SD(SIM) & 58.5 & 34.5 & 32.4 & 22.3 & 17.6 & 1.5 & 2.8 & 3.4 & 0.0 & 12.1 & 22.6 & 60.6 \\
T test & 0.56 & -0.36 & 0.69 & -0.49 & -1.22 & -0.48 & 0.30 & 0.14 & -0.63 & 0.22 & 0.54 & -0.35 \\
PValue & 0.58 & 0.72 & 0.50 & 0.63 & 0.23 & 0.63 & 0.76 & 0.89 & 0.53 & 0.83 & 0.59 & 0.73 \\
F test & 1.10 & 1.80 & 1.62 & 1.23 & 1.97 & 1.47 & 1.46 & 1.34 & 1.56 & 1.46 & 1.50 & 1.02 \\
PValue & 0.79 & 0.08 & 0.14 & 0.55 & 0.05 & 0.26 & 0.25 & 0.38 & 0.19 & 0.26 & 0.22 & 0.94 \\
\hline
\end{tabular}

Table 3: Error indices of AOGCM models

\begin{tabular}{lrrrrrrrrr}
\hline Parameters & $\begin{array}{r}\text { Models } \\
\text { Index }\end{array}$ & CNRCRM3 & GFDLCM2 & HADCM3 & HADGEM & INCM3 & IPSLCM4 & MIHR & NCCCSM3 \\
\hline Precipitation & RMSE & 39.18 & 30.88 & 20.21 & 34.25 & 38.97 & 33.95 & 28.86 & 29.3 \\
& MAE & 34.29 & 18.9 & 13.98 & 21.33 & 28.11 & 21.79 & 20.64 & 20.79 \\
& $\mathrm{NSE}$ & -0.61 & 0.00 & 0.57 & -0.23 & -0.59 & -0.21 & 0.13 & 0.1 \\
& $\mathrm{R}^{2}$ & 0.26 & 0.25 & 0.63 & 0.1 & 0.61 & 0.75 & 0.68 & 0.47 \\
Mean temperature & $\mathrm{RMSE}$ & 3.37 & 1.47 & 1.07 & 4.56 & 2.63 & 1.74 & 1.7 & 1.46 \\
& $\mathrm{MAE}$ & 3.17 & 1.12 & 0.88 & 4.52 & 2.2 & 1.64 & 1.41 & 1.1 \\
& $\mathrm{NSE}$ & 0.85 & 0.97 & 0.98 & 0.72 & 0.91 & 0.96 & 0.96 & 0.98 \\
& $\mathrm{R}^{2}$ & 0.992 & 0.991 & 0.999 & 0.996 & 0.972 & 0.998 & 0.99 & 0.996 \\
\hline
\end{tabular}

Table 4: Parameters of vaziri's method in the base and future period (2046-2065)

\begin{tabular}{lrrrr}
\hline Parameters & \multicolumn{3}{c}{ Scenario } & Base \\
\cline { 2 - 4 } & $\mathrm{B} 1$ & $\mathrm{~A} 2$ & $\mathrm{~A} 1 \mathrm{~B}$ & \\
\hline $\mathrm{P}_{\text {daily }}(\mathrm{mm})$ & 38.6 & 33.9 & 38.8 & 42.3 \\
$\mathrm{P}_{\text {year }}(\mathrm{mm})$ & 277.3 & 266.2 & 263.1 & 334.0 \\
$\mathrm{R}_{60}^{10}$ & 14.4 & 13.7 & 14.4 & 14.9 \\
\hline
\end{tabular}

it is observed, the P-value is higher than 1 per cent for all tests and acceptable simulations are made by the LARS WG5 model in the base period.

\section{Appropriate climate model selection}

Table 3 shows the error indices of different AOGCM models in monthly precipitation and temperature simulation in the base period (1968-2000). The appropriate global climate model is HADCM3 with lowest error index and highest $\mathrm{R}^{2}$.

\section{Daily weather data in the future period (2046-2065)}

In Table 4, the average of maximum daily precipitation, hourly precipitation with 10 -year return period, and mean annual precipitation in the future period under different scenarios are compared with the observed corresponding values in the base period. As can be seen, annual and maximum daily precipitation will reduce in the future period. The highest reduction in maximum daily precipitation is 19.9 per cent under the A2 scenario. Further, in B1 and A1B scenario, we consider the maximum and minimum reduction of mean annual precipitation compared to the base period by 21.2 and 16.9 per cent, respectively. Considering the role of maximum daily precipitation $\left(\mathrm{p}_{\text {daily }}\right)$ in short-term precipitation quantiles, reduction of these values can be expected. Based on Table $8, \mathrm{R}_{60}{ }^{10}$ of A2 scenario is lower than that of other scenarios, which is due to lower $\mathrm{P}_{\text {daily }}$ of A2 compared to other scenarios.

\section{IDF curves of the future (2046-2065)}

Table 5 shows the intensity-duration-frequency data in the base and future periods under different scenarios. Furthermore, the percentage change (\%) of intensities in the future comparing with the base period has been computed and shown in table 5. Also, In Fig. 1, the IDF curves in the 


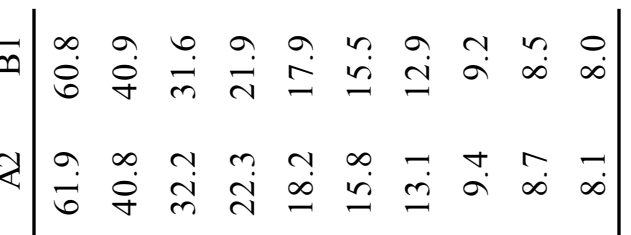

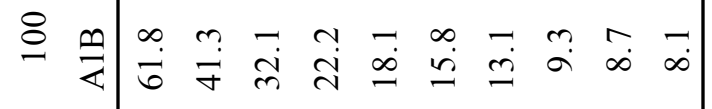

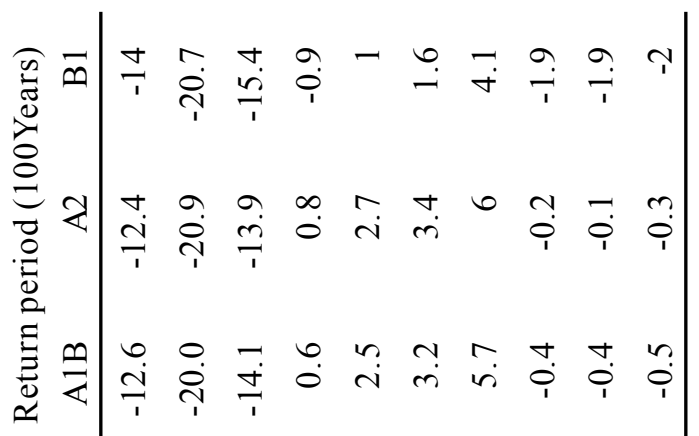



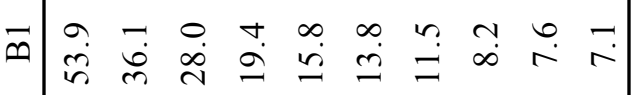

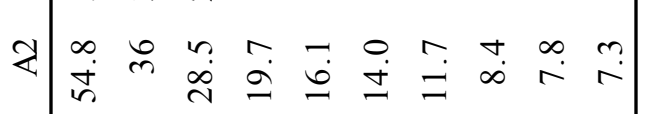

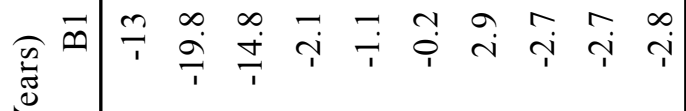

요

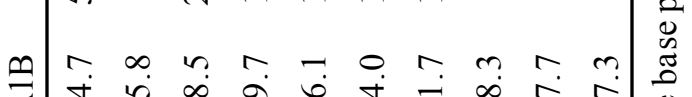

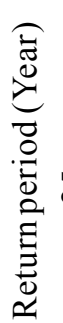

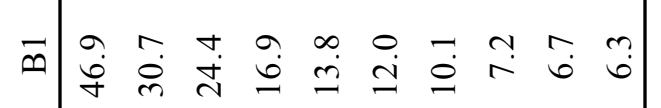

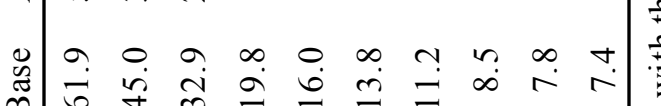

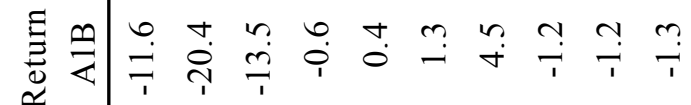

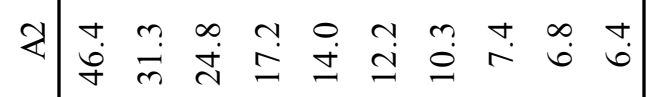

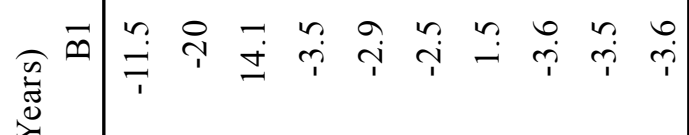

m

守狩离

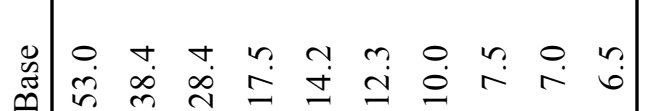

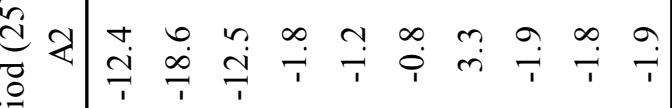

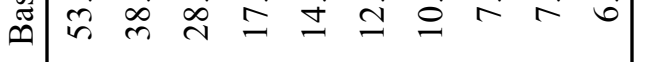

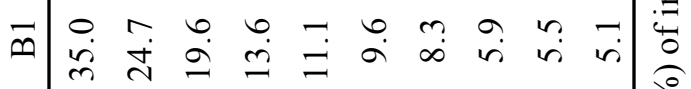

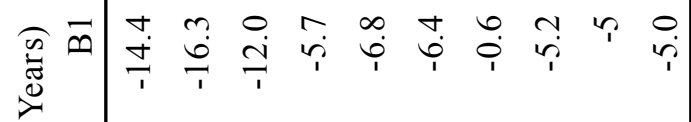

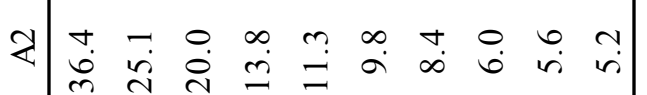

으

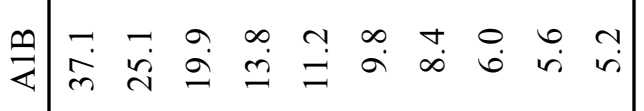

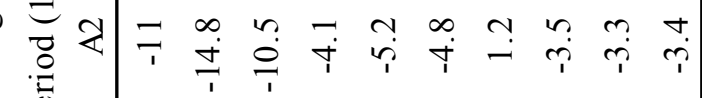

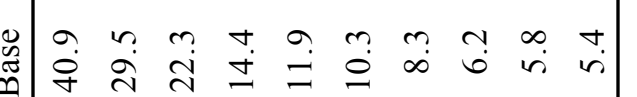

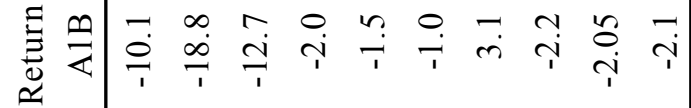

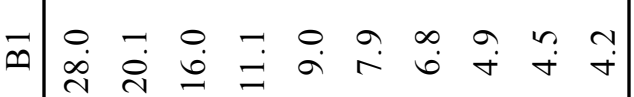

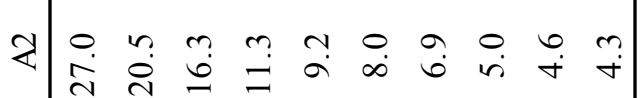

总

in

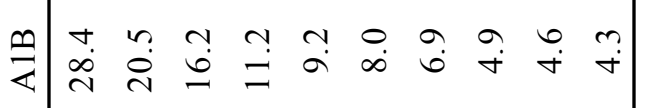

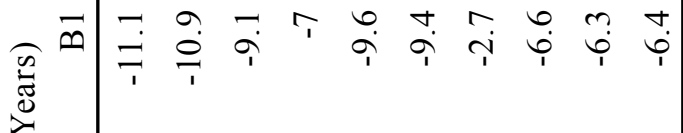

ฮี

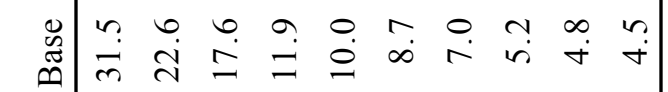

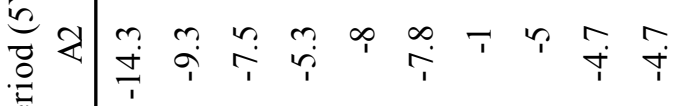

营

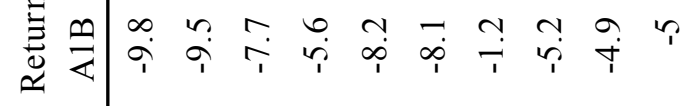


both periods under A2 scenario have been presented. The results indicate, the intensity of the future short-term precipitations across different durations decreases from 0.15 to $10.79 \mathrm{~mm} / \mathrm{h}$, (in average $8.87 \%$ ). Totally, this reduction of intensities is considerable until 1 hour of duration, but after that it is not observable. As can be seen, the highest reduction in precipitation compared to other times is observed in all return periods of all three scenarios at $20 \mathrm{~min}$ (equal $20.9 \%$ reduction in 100 year return period, Fig. 1).

The other study on climate change impacts in Fars Province also suggest increased minimum and maximum temperature and diminished trend of monthly and annual precipitation(Safshekan et al 2017). Despite of most of the studies in the world suggest increasing the precipitation intensity with certain duration at various return periods (Afrin et al 2015; Fadhel et al 2017;Mamo 2015; Solaiman and Simonovic 2011; Zahmatkesh et al 2015), but the result of in this research indicated reduced precipitation intensities in the future period (due to using calibrated Bell type formula) compared to the observed period across all returns periods until $60 \mathrm{~min}$ duration from $0.15 \mathrm{~mm} / \mathrm{hr}$ to $10.79 \mathrm{~mm} /$ $\mathrm{hr}$ (almost equal $8.87 \%$ on average). it is important for urban drainage management. for greater than 60 minutes duration, it shows an intangible change under $\mathrm{A} 1 \mathrm{~B}, \mathrm{~A} 2$, and $\mathrm{B} 1$ scenarios. The result presented in this research is in agreement with the result obtained by Akbari et al. (2015) for Chenar Rahdar Station with a longitude of $52^{\circ} 24^{\prime} \mathrm{E}$ and a latitude of $29^{\circ} 37^{\prime} \mathrm{N}$, which is located near the vicinity of Shiraz synoptic station. However, the difference is that the method employed in the research by Akbari et al. (2015) is based on the observed severe daily precipitation histograms, in which the results suggest diminished intensity of precipitation until $3 \mathrm{~h}$. Further, in their research, time intervals were bigger than compared in this study. Finally,it is suggested that other AOGCM models, other statistical downscaling methods, and other methods for IDF calculation be used. The issue of uncertainty should also be taken into account.

\section{CONCLUSIONS}

Climate change may relatively affect the extreme precipitation and make it necessary updatig the IDF curves. In this paper, the effect of climate change was studied on intensity-duration-frequency curves of Shiraz synoptic station. The result show that the mean annual precipitation, mean monthly precipitation in the first six months of the water year and average of maximum daily precipitation decline in the future period. Further, the mean of maximum and minimum monthly temperature will increase.

\section{REFERENCES}

Afrin, S., Islam, M.M. and Rahman, M.M. (2015). Development of IDF Curve for Dhaka City Based on Scaling theory under Future Precipitation Variability Due to Climate Change. IJESD., 5(6) :332-335.

Akbari, H., Rakhshandehroo, G.R., Afrooz, A.H. and Pourtouiserkani,A. (2015). Climate Change Impact on Intensity-Duration-Frequency Curves in Chenar-Rahdar River Basin. ASCE Watershed Manag., 48-61.

Bakhtiari, B., Purmusavi, Sh. and Sayari, N. (2015). Impact of Climate Change on Intensity-Duration-Frequency Curves of Precipitation(Case study: Babolsar station). Iranian J. Irrig. Drain., 8(4). [In Persian].

Bell, F.C. (1969). Generalized Rainfall-Duration-Frequency Relationship. J. Hydrol., 95(1):311-328.

Chow, V.T., Maidruent, D.R. and Mays, L.W.(1988). “Applied Hydrology" Mcgraw Hill. 572 pp.

Fadhel, S.,Angel, M., Ramirez, R. andHan, D.(2017). Uncertainty of Intensity-Duration-Frequency (IDF) curves due to varied climate baseline periods. J. Hydrol., 547:600612.

Ghahraman, B. and Abkhezr, H.(2004). Improvement in intensityduration-frequencyrelationships of rainfall in Iran.JWSS, No.2. [In Persian].

Ghahraman, B. and Sepaskhah, A.R. (1990). Estimation fo rainfall inteasity-frequency relationship in Iran using ten years maximum hoorly precipitation. Procedding of 3rd Intera. Iranian Corg ofCivil Eng. Shiraz University, Iran, 55-74. [In Persian].

Mamo, T.G. (2015). Evaluation of the Potential Impact of Rainfall Intensity Variation due to Climate Change on Existing Drainage Infrastructure. J. Irrig. Drain. Engg., 141(10).

Mirhosseini, G., Srivastava, P. and Stefanova, L. (2013). The impact of climate change on rainfall Intensity-DurationFrequency (IDF) curves in Alabama. Reg. Environ. Change., 13(1):25-33 .

Pereira, M.G., Fernandes, F.S., Macário, M.B., Gaspar, S.M and Pinto, J.G. (2014). Climate Change Impacts in the Design of Drainage Systems: Case Study of Portugal. J. Irrig. Drain. Engg., 141(2). https://doi.org/10.1061/ (ASCE)IR.1943-4774.0000788. 
Rodríguez, R., Navarro, X., Casas, M.C., Ribalaygua, J., Russo, B., Pouget, L. and A. Redaño.(2014). Influence of climate change on IDF curves for the metropolitan area of Barcelona (Spain). Int. J. Climatol., 34(3):643-654.

Safshekan. F., Akhond Ali, A. M., Haghighi, A. and Zarei, H. (2017). Rainfall-runoff simulation under climate change conditions in catchment of Doroodzan dam in Fars province of Iran. Eco. Environ. Conser. J. Papers., 23(3):1256-1264.

Semnov, V.A. (2011). Climate-related Changes in Hazardous and Adverse Hydrological Events in the Russians Rivers. Russ. Meteorol. Hydrol., 36(2): 124-129.

Singh, S.R., Arya, A.K. and Vojinovic, Z.T. (2016). Potential Impact of Climate Change on Rainfall Intensity-DurationFrequency Curves in Roorkee, India. Water Resour. Manage., 30(13):4603-4616.
Solaiman, T.A. and Simonovic, S.P. (2011). "Development of Probability Based Intensity-Duration-Frequency Curves under Climate Change. Water Resources Research Report no.072, Department of Civil and Environmental Engineering, London, Ontario, Canada.

Vaziri, F. (1991). Analysis of Storam in different party of Iran. Jehad, Daueshgahi of Khajeh Nasir-Al-Diu Toos: University, Design and Research Division, 734 p. [In Persian].

Zahmatkesh, Z., Karamouz, M., Goharian, E. and Burian, S.J. (2015). Analysis of the Effects of Climate Change on UrbanStorm WaterRunoffUsing StatisticallyDownscaled Precipitation Data and a Change Factor Approach. $J$. Hydrol. Engg., 20(7):1-11. 